\title{
Autólise da camada de células granulares do cerebelo em bovinos
}

\author{
Conglutination of the cerebellar granule cell layer in cattle
}

\author{
Raquel Rubia Rech ${ }^{\mathrm{I}}$ Daniel Ricardo Rissi ${ }^{\mathrm{I}}$ Felipe Pierezan ${ }^{\mathrm{I}}$ Adriane Loy Gabriel ${ }^{\mathrm{I}}$ \\ Claudio Severo Lombardo de Barros ${ }^{\text {II }}$
} \begin{abstract}
A autólise da camada de células granulares do
cerebelo é um achado postmortem observado em bovinos e RESUMO relacionado ao prolongado tempo de duração entre a morte e a fixação do encéfalo. Para observar a prevalência desse artefato, 228 cerebelos foram examinados histologicamente ao longo do verme cerebelar. Trinta e seis por cento desses casos apresentaram conglutinação cerebelar não relacionada a doença específica. Em $74,4 \%$ dos casos em que foi observada conglutinação cerebelar, não foram observadas alterações histopatológicas. Histologicamente, a conglutinação cerebelar caracterizou-se por dissolução segmentar ou difusa da camada de células granulares. A descrição deste artefato é importante, pois já foi confundido como lesão relacionada a doença específica do sistema nervoso de bovinos.
\end{abstract}

Palavras-chave: conglutinação cerebelar, "état glacé", neuropatologia, sistema nervoso central, patologia, artefato.

\section{ABSTRACT}

Cerebellar conglutination of the granule cell layer is a postmortem artifact observed in cattle. It is related to increased time between death and fixation of the brain. In this study, 228 cerebellum were histologically analyzed throughout cerebellar vermis. Cerebellar conglutination was observed in $36 \%$ of the cases and it was not related to specific diseases. Seventy-four percent of the cases did not present any histological lesions in the brain. Microscopically, cerebellar conglutination was characterized by segmentar or diffuse dissolution of the granule cell layer. This artifact has been misinterpreted as resulting from specific diseases of the central nervous system in cattle, and it has to be differentiated from important antemortem lesions.
Key words: cerebellar conglutination, 'état glacé', neuropathology, central nervous system, pathology, artifact.

A autólise da camada de células granulares do cerebelo (conglutinação cerebelar ou état glacé) é um artefato observado somente em bovídeos e humanos (SUMMERS et al., 1995; FULLER \& BURGER, 1997). Este achado é considerado um fenômeno postmortem relacionado com $\mathrm{pH}$ baixo no tecido nervoso em autólise (ALBRECHTSEN, 1977).

Em 2005, durante o diagnóstico de rotina, foram examinados 228 encéfalos de bovinos enviados ao Laboratório de Patologia Veterinária (LPV) da Universidade Federal de Santa Maria (UFSM), como parte do sistema de vigilância da encefalopatia espongiforme bovina (BSE). Os fragmentos de encéfalo foram processados rotineiramente para histologia e corados pela hematoxilina-eosina (BARROS \& MARQUES, 2003). Para análise do cerebelo, foi realizado um corte longitudinal ao longo do verme cerebelar.

Dos 228 cerebelos estudados, 82 (36\%) apresentavam autólise da camada de células granulares. Desses 82 cerebelos, 61 (74,4\%) não apresentaram alterações histopatológicas. Dos 21 encéfalos restantes, 12 tinham lesões de encefalopatia hepática, quatro de encefalomalacia focal simétrica (intoxicação

'Programa de Pós-graduação em Medicina Veterinária (PPGMV), Centro de Ciências Rurais (CCR), Universidade Federal de Santa Maria (UFSM), Santa Maria, RS, Brasil.

IIDepartamento de Patologia, UFSM, 97105-900, Santa Maria, RS, Brasil. Email: claudioslbarros@uol.com.br. Autor para correspondência. 
por Ramaria flavo-brunnescens), três de intoxicação por Solanum fastigiatum, um de polioencefalomalacia e um de meningoencefalite não-supurativa inespecífica. Na maioria dos casos, nenhuma alteração macroscópica foi observada nos encéfalos examinados. Ocasionalmente, ao corte do verme cerebelar, observava-se que a região periférica das folhas cerebelares estava fixada e a porção interna apresentava-se parcialmente fixada (rósea-clara) (Figura 1A). Em uma visão submacroscópica, havia palidez das porções profundas das folhas cerebelares (Figura 1B). Histologicamente observou-se rarefação da camada de células granulares (Figura 1C), com dissolução desses pequenos neurônios e preservação dos neurônios de Golgi, das células de Purkinje, da camada molecular e da substância branca do cerebelo (Figura 1D).
A autólise da camada de células granulares é uma alteração postmortem que já foi confundida com necrose isquêmica das células dessa camada e descrita no Japão como uma entidade específica de bovinos, denominada “doença de Kiriyoi” (GOTO et al., 1959; YAMAGIWA \& GOTO, 1959). Observações semelhantes foram feitas na Alemanha (FANKHAUSER \& LUGINBÜHL, 1968). A ausência de outras alterações histológicas associadas à conglutinação cerebelar, como, por exemplo, reação das células gliais, indica que essa alteração não está relacionada com doença neurológica (ESCOURELLE \& POIRIER, 1978).

Em humanos, apesar de esse fenômeno ser mais freqüente em algumas doenças específicas, como diabete ou uremia, foi demonstrado que a conglutinação cerebelar ocorre devido à acidez tecidual que está diretamente relacionada à duração do processo de

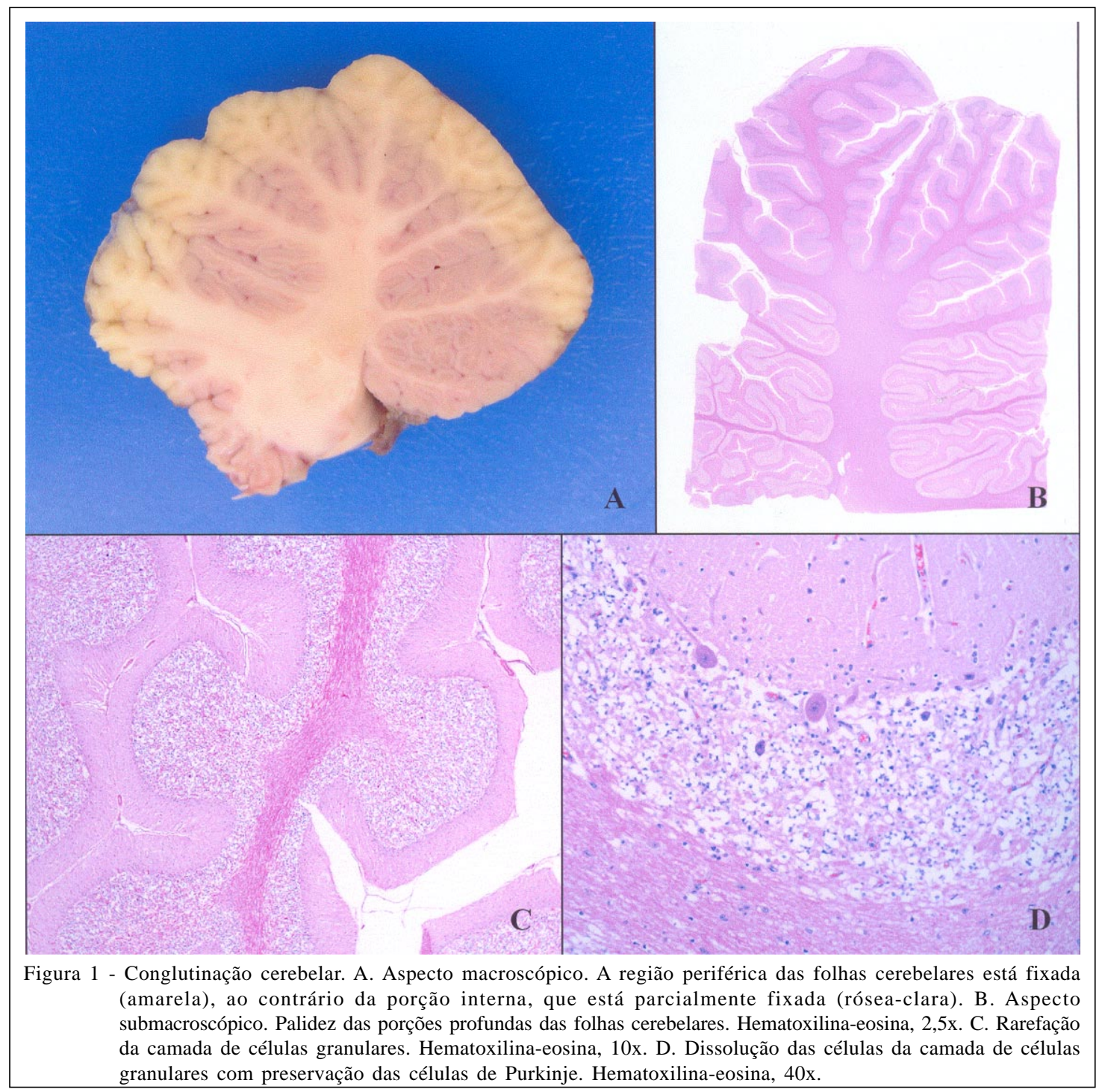

Ciência Rural, v.38, n.4, jul, 2008. 
morte. A patogênese proposta para esse fenômeno foi o aumento da atividade de naftilamidase, uma enzima proteolítica liberada em $\mathrm{pH}$ ácido ( $\mathrm{pH}$ 5,5-5,8) pelos lisossomos, na camada de células granulares em cerebelos de ratos e humanos 100 horas após da morte (ALBRECHTSEN, 1977).

Neste estudo, não houve relação entre conglutinação cerebelar e doença do sistema nervoso central (SNC). Em 74,4\% dos casos em que se observou conglutinação cerebelar, os encéfalos não mostravam quaisquer outras alterações histopatológicas nem sinais de autólise em outros locais. No entanto, em 21 dos bovinos com conglutinação cerebelar (25,6\% de 82 encéfalos) havia sinais clínicos de distúrbios nervosos. Isso indica a importância de separar achados antemortem significativos de artefatos durante o exame histológico do SNC, especialmente quando os encéfalos examinados são de bovinos com sinais clínicos de distúrbios neurológicos.

\section{AGRADECIMENTOS E APRESENTAÇÃO}

Ao Conselho Nacional de Desenvolvimento Científico e Tecnológico (CNPq), pela concessão de bolsa ao pesquisador Rech.

Parte da Tese de Doutorado em Medicina Veterinária do primeiro autor, Programa de Pós-graduação em Medicina Veterinária da Universidade Federal de Santa Maria, área de concentração em Patologia Veterinária.

\section{REFERÊNCIAS}

ALBRECHTSEN, R. The pathogenesis of acute selective necrosis of the granular layer of the human cerebellar cortex. Acta Neuropathologica, v.37, p.31-34, 1977.

BARROS, C.S.L. ; MARQUES, G.H.F. Procedimentos para o diagnóstico das doenças do sistema nervoso central de bovinos. Brasília: Departamento de Defesa Animal, Ministério da Agricultura, Pecuária e Abastecimento, 2003. 50p.

ESCOURELLE, R.; POIRIER, J. Manual of basic neuropathology. Philadelphia : Saunders, 1978. 209p.

FANKHAUSER, R.; LUGINBÜHL, H. Zentrales nervensystem. In: JOEST, E. Handbuch der speziellen patologischen anatomie de hautiere. Berlin: Verlag Paul Parey, 1968. V.3. p.191-436.

FULLER, G.N.; BURGER, P.C. Central nervous system. In: STERNBERG, S.S. Histology for pathologists. Philadelphia: Lippincott-Raven, 1997. Cap.11, p.243-282.

GOTO, M. et al. Pathological studies on so-called "Kiriyoi disease”. Japanese Journal of Veterinary Research, v.7, p.156-170, 1959.

SUMMERS, B.A. et al. Veterinary neuropathology. St. Louis: Mosby, 1995. 527p.

YAMAGIWA, S.; GOTO, M. Cortical cerebellar atrophy of granular type in Japanese cattle. Japanese Journal of Veterinary Research, v.7, p.126-137, 1959. 